
\title{
Comunicação de interesse público e ciberativismo: as ações de sustentabilidade da comunidade virtual Mapa do lixo - Belém (PA) - Amazônia
}

Communication of Public Interest and Cyber-Activism: The Virtual Community Sustainability Actions The Garbage Map - Belém (PA) - Amazônia

\begin{abstract}
L Neusa Pressler
Professora Titular I do Programa de Pós-Graduação em Comunicação, Linguagens e Cultura e do Curso de Comunicação Social ambos da Universidade da Amazônia (UNAMA/Ser Educacional). Pesquisadora Líder do Projeto Agências Digitais na Amazônia Real, certificado pelo CNPq. Doutora em Ciência Socioambiental pelo Núcleo de Altos Estudos Amazônicos (NAEA) da Universidade Federal do Pará.

E-mail: neusapressler@hotmail.com

\section{Vanda do Socorro Furtado Amin}

Doutoranda no Programa de Pós-Graduação em Comunicação, Linguagens e Cultura da Universidade da Amazônia (UNAMA/Ser Educacional). Membro do Projeto Agências Digitais na Amazônia Real, certificado pelo CNPq. Mestre em Comunicação, Linguagens e Cultura pela Universidade da Amazônia (UNAMA/Ser Educacional). Professora da Educação Básica do I Comando de Aeronáutica em Belém, na Escola Tenente Rêgo Barros.

Email: vanda_amin@hotmail.com
\end{abstract}

Recebido em 1 de fevereiro de 2017. Aprovado em 19 de abril de 2017.

\section{Resumo}

Este artigo descreve aspectos da Comunicação de Interesse Público e de ciberativismo nas ações de sustentabilidade da comunidade virtual "O Mapa do Lixo - Belém", Amazônia. O estudo foi realizado em 2016, com as metodologias de pesquisa exploratória e bibliográfica. O corpus é formado por depoimentos da Fanpage e por entrevista realizada com a administradora da página. A investigação mostrou ações de ciberativismo que mobilizam o cidadão belenense sobre a questão do lixo. Os resultados parciais indicam que o ciberativismo funciona como uma estratégia de mobilização social de sustentabilidade ambiental e de cidadania.

Palavras-chave: Comunicação. Ciberativismo. Sustentabilidade. Amazônia. 


\section{Abstract}

This article describes aspects of public interest communication and cyber-activism in the sustainability actions of the virtual community "The Garbage Map", Belém, (Pará) Amazon. The study was conducted in 2016, with exploratory and bibliographic research methodologies. The corpus consists of Fanpage testimonials and an interview conducted by the page administrator. The investigation showed actions of cyber-activism that mobilize the Belenense citizen on the issue of garbage. Partial results indicate that cyber-activism functions as a social mobilization strategy for environmental sustainability and citizenship.

Keywords: Communication. Ciber-activism. Sustainability. Amazônia.

\section{Introdução}

O ciberativismo emerge no ciberespaço como herança dos movimentos ativistas iniciados nas décadas de 1960 e 1970 e, posteriormente, com a pauta midialivrista na década de 1980, por uma mídia democrática e participativa (LÉVY, 1999). É na essência social e colaborativa da internet que a busca pela informação de interesse público e o ciberativismo ganham força, utilizando, entre outros recursos, as redes sociais e as comunidades virtuais.

As redes sociais, como padrões de interação e relações sociais entre as pessoas, na internet, geram novas formas de sociabilidade, uma modalidade emergente que se adapta e se autorganiza, norteada pela intereração, comunicação e circularidade de informações. Raquel Recuero (2009, p. 135) define a rede social virtual como "local, simbólico e delimitado onde grupos de afinidades subjetivas se encontram, compartilham emoções e trocam experiências", sendo promotora de coesão e de manutenção de grupos sociais.

As sociais media e suas comunidades têm sido um aliado nas manifestações ativistas ou na militância ciberativista, com implementação de ações, entre outras, em defesa do meio ambiente e da educação ambiental. Isso não é por acaso, de acordo com a Pesquisa Brasileira de Mídia 2016, a internet é o meio que está com maior ascensão, sendo o mais popular entre os jovens, registrando-se intensa exposição na rede, que corresponde a 76\% de ocorrência durante todo o dia (BRASIL, 2016).

Ainda conforme essa pesquisa governamental, o uso de aparelhos celulares como forma de acesso à internet já compete com o uso por meio de computadores ou notebooks, chegando a $66 \%$ e $71 \%$, respectivamente. O uso de social media influencia esse resultado, uma vez que $92 \%$ dos internautas estão conectados por meio de redes sociais, sendo as mais utilizadas o Facebook (83\%), o WhatsApp (58\%) e o YouTube (17\%) (BRASIL, 2016, p.7). 
Ao longo deste artigo, destacaremos dados do uso e do consumo das redes sociais, as quais optamos denominar de social media por se tratar de um estudo focado nas relações sociais do ciberativismo. Desse modo, o termo social media é o que melhor se ajusta à explicação e ao entendimento desse fenômeno no espaço virtual, no que se refere à busca de informação de interesse público e às ações de ciberativismo.

Os dados estatísticos mencionados indicam que o uso das redes sociais (social media), além de possibilitar a facilidade de composição de relacionamentos entre pessoas com interesses e disposições afins, está transformando o consumidor em um produtor de conteúdo. Dessa forma, a cibercultura e o ciberativismo têm uma relação direta com a cultura contemporânea, pois é o resultado do desenvolvimento da cultura técnica moderna.

Sob a perspectiva de que a comunicação digital está modificando o comportamento e o relacionamento social, como demonstram, em certa medida, pesquisas sobre consumo de mídia em busca de Comunicação de Interesse Público e as ações de ciberativismo, este artigo descreve e reflete sobre ações de ciberativismo promovidas pela página "Mapa do Lixo - Belém". Nesse sentido, o trabalho estrutura-se em quatro tópicos: sustentabilidade ambiental na Amazônia; discussão sobre o descarte do lixo na cidade de Belém (PA); a Comunicação de Interesse Público e dados sobre resíduos (lixo); comunidade "Mapa do Lixo - Belém" e ciberativismo.

\section{Sustentabilidade ambiental na Amazônia}

O conceito de desenvolvimento sustentável emerge no contexto da crise ecológica, havendo, pelo menos, duas correntes de discussão nesse processo. Uma primeira, centrada no trabalho do Clube de Roma, reuniu suas ideias e publicou-as em 1972 sob o título de Limites do crescimento. Essa vertente objetiva alcançar a estabilidade econômica e ecológica propondo o congelamento do crescimento da população global e do capital industrial, demonstrando a realidade dos recursos limitados e indicando uma forte tendência para o controle demográfico.

A segunda corrente, relacionada à crítica ambientalista e ao modo de vida do consumo contemporâneo, foi difundida a partir da Conferência de Estocolmo em 1972. Seus princípios estão baseados no pressuposto da existência de sustentabilidade social, econômica e ecológica (PRESSLER, 2012, p. 126). Assim,

Estas dimensões explicitam a necessidade de tornar compatível a melhoria nos níveis e qualidade de vida com a preservação ambiental. Surge para dar uma resposta à necessidade de harmonizar os processos ambientais com os socioeconômicos, maximizando a produção dos ecossistemas para favorecer as necessidades humanas presentes e futuras. A maior virtude 
dessa abordagem é que, além da incorporação definitiva dos aspectos ecológicos no plano teórico, ela enfatiza a necessidade de inverter a tendência auto-destrutiva dos processos de desenvolvimento no seu abuso contra a natureza (JACOBI, 1997, p. 5).

No contexto brasileiro, essa questão ambiental vem desenvolvendo o conceito de sustentabilidade, que é introduzido de acordo com as informações do Ministério do Meio Ambiente. A partir da Conferência das Nações Unidas sobre Meio Ambiente e Desenvolvimento (CNUMAD), celebrada no Rio de Janeiro em 1992, o debate internacional sobre florestas alcançou importante papel na agenda internacional.

Dessa forma, as questões relacionadas ao manejo sustentável dos recursos florestais e à sustentabilidade tiveram um tratamento abrangente e passaram a ser requisitos importantes nas negociações internacionais. A partir de então, alguns documentos e eventos relacionados às questões de florestas contribuíram, sobremaneira, para o debate ambiental.

Nesse cenário mundial, o Brasil enquadra-se como "país emergente”, atuando com um crescimento bastante significativo desde o início deste milênio, buscando estar menos vulnerável às intempéries das oscilantes crises financeiras mundiais, especialmente no que diz respeito às esferas sociais e políticas. Ressalte-se que o desenvolvimento de forma sustentável, como tem sido proposto pelos países do $\mathrm{G}^{1}$, ainda é um desafio, no âmbito regional e local no Brasil (PRESSLER, 2012, p. 128).

Um dos elementos relevantes para a realização do desenvolvimento são os processos de implantação e de promoção de projetos que preservam a natureza em que se agregam valores em prol da sustentabilidade do planeta. Nesse contexto, encontra-se o debate sobre a Amazônia, seu desenvolvimento, a sustentabilidade e o meio ambiente. Seguindo a tendência global, a maioria dos projetos socioambientais na Amazônia e as ações do Ministério do Meio Ambiente (MMA) e de instituições bilaterais, como o Banco Mundial e, posteriormente, a aprovação do Programa Piloto para a Proteção das Florestas Tropicais ${ }^{2}$ (PPG7) na região, imprimem essa visão de sustentabilidade e de práticas sustentáveis na Amazônia (1995-2009).

1 Grupo de sete países mais industrializados e desenvolvidos economicamente do mundo: Estados Unidos, Alemanha, Canadá, França, Itália, Japão, Reino Unido. Instituído em 1975 pelo presidente francês Valéry Giscard d'Estaing, que teve a iniciativa de reunir os chefes de Estado e de governo da Alemanha, dos Estados Unidos, do Japão, da Itália, do Reino Unido, em um primeiro momento e, depois, teve a adesão do Canadá (PRESSLER, 2012, p.71).

2 O Programa Piloto foi proposto na reunião do Grupo dos Sete países industrializados (G7), em Houston, Texas (EUA), em 1990. Em dezembro de 1991, foi aprovado pelo G7 e pela Comissão Europeia. Durante a Eco-92, o programa foi oficialmente lançado no Brasil. A sua execução foi competência do governo brasileiro que, por meio do Ministério do Meio Ambiente, o qual coordenou o Programa; contou ainda com o 
A introdução do PPG7 desempenhou um papel importante na expectativa de reformulação das políticas públicas para a Amazônia, apresentando resultados que se tornaram modelos para políticas de gestão ambiental no Brasil (BRASIL, 2009a, p. 4). Instituído em 1992 e introduzido em 1995, o PPG7 reuniu financiamentos dos sete países mais ricos do mundo e da União Europeia em ações que valorizam o uso sustentável dos recursos naturais, nos países em desenvolvimento. Esse programa estimula iniciativas que ampliem o conhecimento dos ecossistemas, diminuam a emissão de carbono e reforcem as decisões locais para a melhoria da qualidade de vida das populações.

A consulta ao catálogo de publicações do PPG7, editado pelo MMA³ em 2009, especialmente o resumo dos principais projetos no decorrer de 17 anos de atuação na Amazônia e na Mata Atlântica, revela vários enunciados e enunciadores que caracterizam uma prática polifônica (BRASIL, 2009b). Os enunciados “desenvolvimento", "meio ambiente", "desenvolvimento sustentável e "sustentabilidade" estão presentes em quase todas as publicações divulgadas no catálogo, confirmando as representações de diferentes vozes, somadas a novos discursos em torno de interesses comuns (PRESSLER, 2012, p. 231).

Desse modo, os termos "capital social", "preservação ambiental", "manejo sustentável" e "sustentabilidade", implícitos nos temas da "agenda global", foram disseminados em diversos discursos e estão presentes na comunicação institucional dos projetos socioambientais implantados em várias regiões da Amazônia e também difundidos em organizações locais como a Secretaria do Meio Ambiente (SEMA), entre outros.

Entretanto, houve um vácuo nessa comunicação institucional de interesse público no que diz respeito à recepção pelos diferentes públicos quanto à difusão do conhecimento de práticas sustentáveis ambientais, as quais ficaram restritas à floresta e aos agentes sociais participantes dos projetos ambientais. Apesar do valor investido nos projetos ambientais, no âmbito das consultorias técnicas internacionais, acreditava-se que as sociedades urbanas na Amazônia não precisariam de projetos regionais ou locais para o desenvolvimento da educação ambiental.

Assim, passados mais de vinte anos da Eco 92 e do início dessas práticas sustentáveis, depara-se com a situação da ausência de Comunicação de Interesse Público para a conscientização sobre o acondicionamento e o descarte dos resíduos sólidos (lixo) na

intermédio do Ministério da Justiça e do Ministério da Ciência e Tecnologia, com a participação do Banco Mundial, da Comunidade Europeia e dos países membros do G7. O PPG7 foi instituído pelo Decreto n ${ }^{\circ} 563$, em junho de 1992, e modificado pelo Decreto $\mathrm{n}^{\circ} 2.119$ em janeiro de 1997. Os primeiros projetos foram aprovados em 1994 e a introdução, iniciada em 1995. Fonte: <http://www.mma.gov.br/ppg7> Acesso em: 17 jun. 2016.

3 Ver mais detalhes sobre as publicações: Catálogo de publicações do Programa Piloto para Proteção das Florestas Tropicais do Brasil: 17 anos de atuação na Amazônia e Mata Attântica. Brasília: MMA (BRASIL, 2009b). 
cidade de Belém (PA). O estado do Pará foi contemplado com vários projetos ambientais do PPG7, mas em Belém, capital do estado, ruas, canais e rios são sujos, mal preservados. Muitas ruas têm asfalto e calçadas com buracos e lixo por toda parte.

A imagem de preservação ambiental e sustentabilidade é frágil, pois mostra não só a ausência de Comunicação de Interesse Público, como também a escassez de serviços públicos para a manutenção da limpeza e o recolhimento dos detritos. Especialmente quanto à questão do gerenciamento do lixo, as imagens divulgadas em sites, como a página "Mapa do Lixo - Belém", e em pesquisas jornalísticas e acadêmicas apontam a falta/distorção de consciência ambiental por parte das autoridades públicas e da sociedade belenense.

\section{Discussão sobre o descarte do lixo na cidade de Belém (PA)}

A cidade de Belém, localizada na região norte do Brasil, é a capital do estado do Pará. Com uma população de 1. 392.031 habitantes é a maior densidade demógrafica da região norte, com 1307,17 hab/ $\mathrm{km}^{2}$ (INSTITUTO BRASILEIRO DE GEOGRAFIA E ESTATÍSTICA, 2010), sendo referida no Portal de Turismo do Estado do Pará como a "Metrópole da Amazônia". Conforme dados estatístiscos, Belém é o segundo maior destino de turistas na Amazônia Legal ${ }^{4}$, ocupando uma área de aproximadamente 1.059.402,00 $\mathrm{Km}^{2}$. O estado do Pará também apresenta uma porção insular composta por 39 ilhas, que corresponde a 33.203,67 ha ou 65,64\% de todo o estado. A taxa de urbanização de Belém é superior à observada em relação ao conjunto da Amazônia e ao estado do Pará (MAIA e GAIA, 2012).

Com essa grandiosidade espacial e demográfica, a cidade é internacionalmente conhecida e exerce influência nacional do ponto de vista cultural, econômico e político. No entanto, não se percebem, na cidade, políticas públicas de educação ambiental, tampouco um planejamento de gestão de resíduos sólidos urbanos que envolva todas as camadas sociais do estado paraense. Há políticas públicas e planejamento urbano para a gestão dos resíduos sólidos (acondicionamento, descarte e reciclagem), todavia, na prática, não há gerenciamento e eficácia, tampouco informações públicas sobre o assunto (PARÁ, 2011).

4 A Amazônia Legal é uma área que engloba nove estados brasileiros pertencentes à Bacia amazônica e, consequentemente, possuem em seu território trechos da Floresta Amazônica. O governo brasileiro, com o intuito de melhor planejar o desenvolvimento social e econômico da região amazônica, instituiu o conceito de Amazônia Legal. Para isso, tomou como base análises estruturais e conjunturais, reunindo regiões de idênticos problemas econômicos, políticos e sociais. Desse modo, a atual área de abrangência da Amazônia Legal corresponde à totalidade dos estados do Acre, Amapá, Amazonas, Mato Grosso, Pará, Rondônia, Roraima, Tocantins e parte do estado do Maranhão (a oeste do meridiano de $44^{\circ}$ de longitude oeste), perfazendo uma superfície de aproximadamente $5.217 .423 \mathrm{~km}^{2}$ correspondente a cerca de 59\% do território brasileiro (IBGE, 2017). 
Em 2015, segundo a Secretaria Municipal de Saneamento de Belém (SESAN) a Prefeitura mapeou e identificou mais de 600 pontos críticos de despejo irregular de lixo na capital e flagrou 350 carrinheiros (que costumam fazer o despejo irregular do lixo), os quais tiveram as carroças apreendidas. Essa descrição acerca da produção e do descarte do lixo na cidade mostra uma situação de calamidade e desleixo por parte do cidadão, que não se vê na obrigação de manter a cidade limpa e de cuidar da produção e do descarte dos resíduos, assim como por ação do poder público, que não mostra interesse em estruturar e criar um planejamento urbano para a gestão dos resíduos sólidos. A Figura 1 ilustra essa situação de descaso.

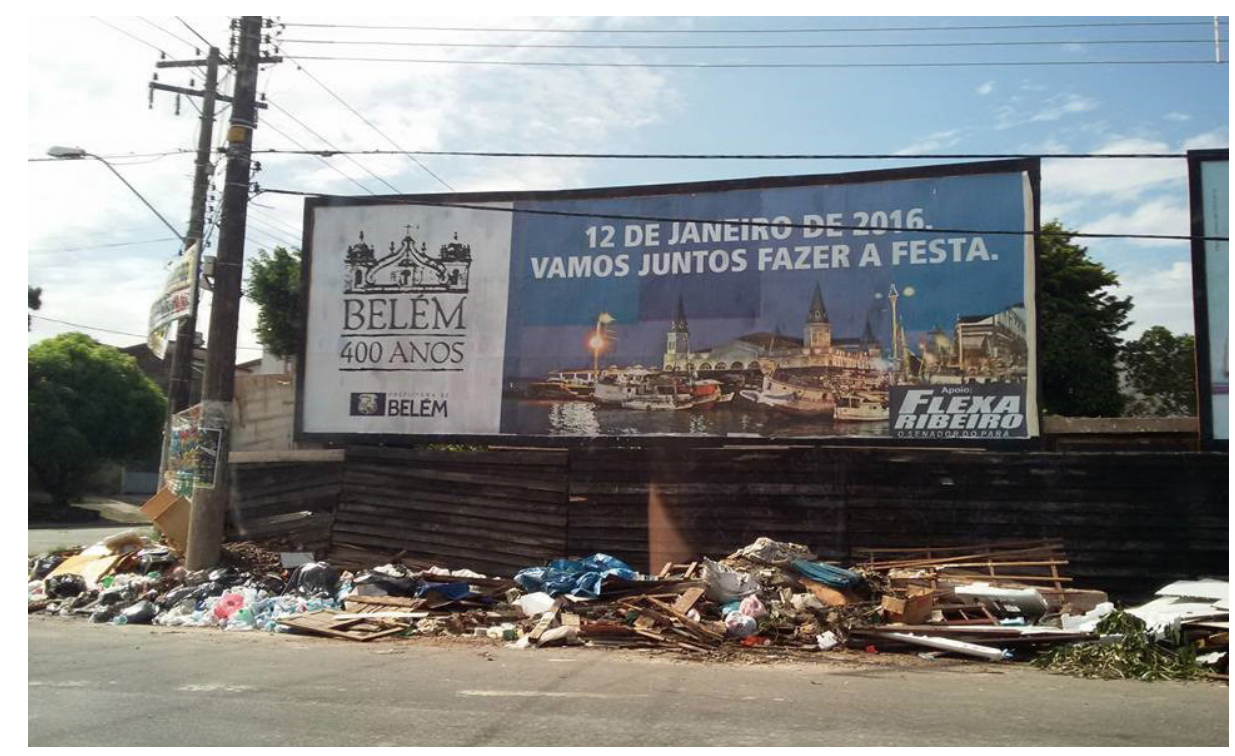

Figura 1. Rua Antônio Overdosa - Bairro Pedreira, Belém

Fonte: Facebook (jun., 2016)

Repercute ironicamente a quantidade de lixo amontado embaixo do outdoor da prefeitura, o qual faz referência ao aniversário de 400 anos da cidade de Belém, em 12 de janeiro de 2016. Esse local, que também é um ponto de ônibus, integra a lista de descaso do poder público e do cidadão. Conforme a postagem com hashtag \#mapadolixobelém, em 26 de janeiro de 2016, esse lugar ficou intransitável, sujo e com lixo por vários dias.

\section{A Comunicação de Interesse Público e dados sobre resíduos (lixo)}

A Comunicação de Interesse Público (CIP) é um dispositivo que almeja promover benefícios concretos à sociedade ou à parte dela, contribuindo para o exercício de cidadania por meio das ferramentas e dos recursos de comunicação. Seu objetivo é possibilitar

\footnotetext{
$90 \frac{\text { Comunicação \& Inovação, PPGCOM/USCS }}{\text { v. 18, n. } 37 \text { (84-102) maio-ago } 2017}$
} 
reflexões e ações que resultem na realização de melhorias da qualidade de vida do cidadão nos diferentes âmbitos de sua atuação.

Na contemporaneidade, com acesso à comunicação digital, a CIP pode acontecer por meio de produção radiofônica, exibição de filmes, anúncios, eventos, fóruns de discussão on-line, sites, blogs, cartazes impressos, assessoria de imprensa, postagens nas redes sociais ou por meio de outros produtos ou serviço midiático.

De maneira geral, é possível dizer que a CIP entrou na lista de prioridades da sociedade e de seus dirigentes no fim do século XX, quando o interesse pela sustentabilidade, responsabilidade social, democracia e cidadania se consolidou, e passou a ocupar um espaço de maior prioridade para a sociedade no contexto da agenda global. Passados alguns anos, os modelos de exercício da CIP foram se adequando às necessidades dos espaços públicos e democráticos e se tornaram diversos. A comunicação política, a comunicação institucional, as parcerias Público-Privadas (PPP) e a comunicação mercadológica são exemplos de segmentação que encontraram lugar na Comunicação de Interesse Público contemporânea.

Este estudo parte do pressuposto teórico de que a comunicação pública é um espaço favorável para as deliberações públicas e colaborativas, com abordagens acerca da informação comprometida com a cidadania norteada por tendências democráticas de produção, recepção e circulação social (ANTOUN e MALINI, 2013). Desse modo, delimita-se o objeto desta pesquisa pela comunicação relacionada ao "interesse público", compreendendo o ciberativismo como importante ferramenta de mobilização para as práticas sustentáveis de convivência no espaço urbano amazônico

Assim, as premissas das reflexões são extraídas do debate sobre comunicação pública, em que diversos estudiosos no Brasil, a exemplo de Jorge Duarte (2009) e Heloísa Matos (1999), sugerem a necessidade de discuti-la no atual contexto democrático do país, especificamente, após a fase de redemocratização e após a elaboração da Constituição Federal de 1988. Esses autores explicitam o interesse público como norteador da atual comunicação social.

No que se refere ao termo "interesse público", os referidos autores advertem que há dificuldades e contradições para uma conceituação mais precisa. Desse modo, inexistindo o consenso conceitual, parte-se do pressuposto de que há uma interpretação que reconhece o Brasil como um país democrático voltado às práticas de cidadania, condição assegurada pela Constituição de 1988. Em virtude da interligação entre comunicação pública e questões desse mesmo ramo, e dada a sua visibilidade nesse espaço, este estudo também considera a Constituição de 1988 (BRASIL, 1988) como o marco referencial que impulsionou deliberações no âmbito da comunicação de interesse público e institucional. 
No entanto, cabe destacar ainda que entre os autores da temática há diferentes compreensões sobre os dispositivos constitucionais referentes ao acesso de direitos normatizados quanto à efetivação da comunicação pública deliberativa.

\begin{abstract}
Num país em que a desigualdade é enorme, a oportunidade de um cidadão comum conhecer as possibilidades de participação, instrumentos de acesso, seus direitos à informação, a expressar sua opinião ou a um atendimento digno tende a ser equivalente à sua posição na estrutura social. Informação é um bem de interesse geral ainda acessível para poucos, o que restringe o potencial de participação em termos igualitários, tanto de acesso quanto de capacidade de tomar decisões (DUARTE, 2009, p. 67).
\end{abstract}

Como afirma o referido autor, as desigualdades sociais existentes no Brasil atingem também o cidadão no quesito de direito à informação e à comunicação. Entende-se, portanto, que esse quadro torna o tema da comunicação pública mais complexo e instigante. De forma correlata a outros direitos como saúde e educação, o direito à comunicação também requer a adoção de posturas críticas, de ações alternativas de acesso e de práticas não restritas ao poder público.

Nesse contexto, o chamado terceiro setor ou a sociedade civil organizada passa a ocupar um lugar de destaque em atuações que visam à difusão de informações e à formação de consciência crítica, especialmente por meio de movimentos possibilitados no ciberespaço.

Elizabeth Brandão (2009) corrobora a perspectiva de que a comunicação pública não deve se restringir ao poder de atuação do Estado, defendendo que este estabeleça um fluxo permanente com os cidadãos. Por meio da ação colaborativa, o direito à comunicação se perfaz como meio de possibilitar a efetivação da cidadania e de melhorar a qualidade de vida social.

Desse modo, comunicação pública é compreendida como espaço de discussão e de possibilidade de participação dos cidadãos na configuração da vida pública. Nesse sentido, a informação é entendida como um bem público e o acesso a ela é um direito fundamental para o funcionamento democrático da sociedade, a qual é essencialmente comunicativa.

A pesquisa empírica deste trabalho é composta por documentos institucionais, depoimentos coletados na página "O Mapa do Lixo - Belém", no Facebook, e por uma entrevista realizada com a administradora da página. Com isso, foi possível formar um entendimento sobre as ações de busca de informações públicas para a manutenção da limpeza ambiental da cidade de Belém por meio de práticas ciberativistas. 
O Brasil, no campo da comunicação, apresenta uma situação contraditória, especificamente em relação à difusão da informação cidadã e às políticas de comunicação que assegurem o acesso à Comunicação de Interesse Público. Enquanto a alta tecnologia é predominante nas estruturas organizacionais públicas e privadas, coexiste no espaço público um certo desleixo no fluxo informacional de alguns temas, como, por exemplo, os motivos e razões de se manter a cidade limpa e correlacionar essa necessidade à questão de saúde, bem-estar e qualidade de vida das populações.

Todos os dias, Belém produz, em média, 1.800 toneladas de lixo, o que representa, aproximadamente, 200 caminhões-caçamba cheios (SECRETARIA MUNICIPAL DE SANEAMENTO DE BELÉM, 2016). Ressalte-se que uma boa parte dos resíduos corresponde ao lixo doméstico, aquele produzido dentro das casas e que poderia ter outro destino, o reaproveitamento. Ainda, segundo a Secretaria de Saneamento, os funcionários responsáveis pela limpeza pública realizam o serviço de coleta de lixo e resíduos diariamente. Em alguns canais, "a limpeza é feita pelo menos três vezes por semana, mas não parece ser suficiente para o volume de lixo despejado".

Alguns funcionários que fazem a limpeza dos canais afirmam: "Você tira (o lixo) hoje pela manhã e à tarde já tem de novo. Está faltando educação ambiental mais rigorosa para a população". Nesse contexto, cabe a indagação: a reciclagem poderia ser alternativa para lixo produzido na Grande Belém?

Desde setembro de 2015, a cidade conta com dezesseis pontos de coleta seletiva de lixo reciclável. Esses locais estão acessíveis apenas para moradores do bairro de Nazaré, no centro histórico de Belém. Os moradores de outros bairros podem entregar o material reciclável nos galpões localizados na travessa Padre Eutíquio 2647 e em outros locais informados pela prefeitura de Belém (SECRETARIA MUNICIPAL DE SANEAMENTO DE BELÉM, 2016).

Nos dias atuais, a produção de lixo e o seu tratamento têm sido apresentados como um dos maiores desafios de vários países por todo o mundo, principalmente nas grandes metrópoles e centros urbanos. O desenvolvimento urbano e demográfico tem, por consequência, aumentado exponecialmente a produção de resíduos sólidos, emergindo, assim, um problema ambiental e social. Para Associação Brasileira de Normas Técnicas (ABNT), resíduos sólidos ou lixo pode ser definido como resíduos nos estados sólido e semissólido, que resultam de atividades de origem industrial, doméstica, hospitalar, comercial, agrícola, de serviços e de varrição (ASSOCIAÇÃO BRASILEIRA DE NORMAS TÉCNICAS, 1987).

A partir da Política Nacional de Resíduos Sólidos (PNRS), em 2010, esses resíduos têm sido conceituados como materiais, substâncias, objetos ou bens descartados 
resultantes de atividades humanas em sociedade, aos quais a destinação final se procede, propõem-se a proceder ou se está obrigado a proceder. Eles podem se apresentar em estado sólido, líquido e gasoso, recebendo a classificação em: resíduos domiciliares; resíduos de limpeza urbana; resíduos sólidos urbanos; resíduos de estabelecimentos comerciais e prestadores de serviços; resíduos dos serviços públicos de saneamento básico; resíduos industriais; resíduos de serviços de saúde; resíduos da construção civil; resíduos agrossilvopastoris; resíduos de serviços de transportes; e resíduos de mineração (POLÍTICA NACIONAL DE RESÍDUOS SÓLIDOS, 2012).

Segundo Roberta Oliveira (2012) e a Associação Brasileira de Empresas de Limpeza Pública (ABRELPE), em 2010, o Brasil gerou cerca de 61 milhões de toneladas de resíduos sólidos urbanos (RSU), o que representa cerca de 378 quilos/habitante/ ano. Na cidade de Belém, conforme o Plano de Gerenciamento de Resíduos Sólidos do Município referido por Oliveira, produziram-se aproximadamente 908 ton/dia de resíduos sólidos, incluindo resíduos oriundos de coleta domiciliar, feiras e mercados, comércio e resíduos hospitalares. Esses números representaram uma produção de aproximadamente 651 gramas/habitante/dia, tendo a média mensal de resíduos gerados nos domicílios de Belém, de aproximadamente $11.280,00$ toneladas, o que corresponde a cerca de $42 \%$ de todo o lixo gerado na cidade (OLIVEIRA, 2012, p. 50).

Ainda de acordo com Oliveira (2012) e com o IBGE, em 2010 a coleta domiciliar de Belém correspondia à coleta de $97 \%$ dos domicílios, tendo os 3\% restantes dos resíduos sido despejados em terrenos baldios e lançados às margens dos canais. Ressalte-se que a prática de despejar lixos nas proximidades dos canais é um dos principais problemas enfrentados pela Secretaria de Saneamento, para manter a cidade limpa e evitar a proliferação de doenças epidêmicas.

Dos 144 municípios do estado do Pará, apenas 45 coletam o lixo e oferecem tratamento a ele, enquanto 65 fazem coleta diariamente sem tratamento e 24 não fazem coleta. Quanto aos resíduos industriais, apenas 16 fazem controle de tratamento e 128 não possuem qualquer forma de controle. $\mathrm{O}$ ideal de investimentos deveria ser de 10 a $15 \%$ do orçamento de cada município. Somente a Região Metropolitana de Belém (RMB) produz 1800 toneladas de lixo diariamente, sendo que 832 não são recolhidas (OLIVEIRA, 2012, p. 58).

Como apresentado na Figura 1, o lixo que não recolhido é deixado nas ruas e espahado pelas fortes chuvas que o acabam levando para o entorno da cidade, em que dezenas de famílias organizam sua existência material e social em função das águas da Baía do Guajará e do Rio Guamá, já que muitos são pescadores e extratores que ocupam as ilhas ao sul de Belém: Jussara, Maracujá, Papagaios e Itacoãzinho, entre outras. Das 39 ilhas próximas à 
cidade de Belém, somente quatro têm coleta de lixo regular: Jutuba, Cotijuba, Mosqueiro e Outeiro (PROJETO NOVA CARTOGRAFIA SOCIAL DA AMAZÔNIA, 2010).

O lixo deixado nas calçadas da cidade ou jogado nos canais e igarapés é empurrado pela "maré" e avança em direção ao centro das ilhas. Quando a água desce, as garrafas, latas e sacolas plásticas ficam presas à vegetação. De acordo com uma matéria publicada nos cadernos do Proea e postada no "Mapa do Lixo - Belém", os resíduos são mais visíveis na Ilha das Onças e na Ilha Maracujá, as duas que estão localizadas exatamente em frente à cidade.

Com a ausência de consciência ambiental da população urbana de Belém e com o descuido das autoridades para com o tratamento do lixo, as populações tradicionais ribeirinhas experimentam a destruição dos recursos (pesqueiros, vegetais e animais) e, com isso, os problemas de sustentabilidade das unidades domésticas. A desestruturação dos modos de vida desses grupos avança sob o olhar indiferente do Estado e da sociedade urbana que os invisibiliza, produzindo os dejetos e a poluição em escala incontrolável, que chega com cada "maré". Trata-se de antigos ocupantes das ilhas que se dedicam à pesca, ao manejo e ao cultivo do açaí e de cacau (PROJETO NOVA CARTOGRAFIA SOCIAL DA AMAZÔNIA, 2010)

Nesse contexto, além da veiculação desse tema na mídia nacional e local, emergem vários movimentos em prol da limpeza da cidade de Belém. Políticos do Partido Verde, Grupo de Combate ao Lixo "Belém - Cidade Linda", a ONG "No Olhar" e a comunidade virtual "Mapa do Lixo - Belém", entre outras. Essas iniciativas propõem contribuir para o desenvolvimento sustentável através de ações educativas e para o despertar socioambiental e a conservação do meio ambiente. A página "Mapa do Lixo - Belém” vai além dessas ações, objetivando construir um mapeamento com um relatório do projeto Mapa do Lixo - Belém, um documento que está sendo elaborado para o envio futuro à Prefeitura de Belém e ao Ministério Público Estadual.

\section{Comunidade "Mapa do Lixo - Belém" e Ciberativismo}

No ano de 2015, a jornalista Dominik Giust criou a página "O Mapa do Lixo Belém”. Segundo Giust, a ideia da página surgiu porque ela mora em frente a um lixão, formado em um terreno baldio, no bairro do Jurunas, na periferia da cidade de Belém. Sensibilizada, então, com o despejo de lixo irregular frequente e em diferentes lugares do centro urbano de Belém, ela desenvolveu, a partir de sua empresa Sorella Conteúdo e em parceria com a Associação dos Biólogos no Pará (ABIOPA), o projeto "Mapa do Lixo - 
Belém". Como parte desse projeto, criou uma página no Facebook intitulada "Mapa do Lixo - Belém". De acordo com Giust,

Diariamente, vejo ser despejado todo tipo de material, como caroços de açaí, restos de madeira, móveis velhos, caixas com gatos vivos, bichos mortos. Há períodos em que o odor fica insuportável. A rua inteira fica suja. O lixo chega a entrar no prédio onde moro (GIUSTI, 2016a).

Ao identificar a ausência de Comunicação de Interesse Público para conscientizar o cidadão belenense em manter a cidade limpa, a jornalista teve a iniciativa de fazer algo mais efetivo, que pudesse trazer impacto de mudança para esse cenário. Assim, planejou algo mais concreto como o "Mapa do Lixo - Belém", objetivando "exatamente mapear esses locais e fazer um grande relatório imagético, um memorial do lixo" (GIUSTI, 2016a). A página "Mapa do Lixo - Belém" pode ser acessada por qualquer pessoa, que também colabora com o mapeamento proposto pela jornalista. Para isso, basta postar uma fotografia de uma local em que encontrou lixo e usar a hashtag \#mapadolixobelém ${ }^{5}$. A partir desse marcador, Dominik reúne as imagens dos colaboradores dessa comunidade virtual e assim alimenta a rede.

Dessa maneira, iniciaram-se as ações da comunidade virtual "Mapa do Lixo Belém", na social media Facebook. Seu objetivo é desenvolver um relatório imagético, com fotografias e vídeos, e o mapeamento dos pontos de depejo de lixo irregular, além de promover a educação ambiental e a discussão sobre o lixo, o meio ambiente e a sustentabilidade.

A imagem da lata de lixo, o destaque da letra $\mathrm{X}$ e o pontilhado sugerem sentidos (Figura 2) de ações de localizar os resíduos e colocá-los no recipiente adequado e de forma contínua. Apesar de sua logomarca não apresentar as cores padrões da percepção ambiental (verde, amarelo, azul) ${ }^{6}$, a plataforma da comunidade em questão desenvolve um trabalho social muito significativo no contexto urbano.

Uma parte do projeto se completará com as oficinas de comunicação comunitária que Giusti pretende realizar em parceria com outros jornalistas e escolas públicas de

5 Hashtag é uma expressão bastante comum entre os usuários das redes sociais, na internet. É uma palavra-chave antecedida pelo símbolo \#, conhecido popularmente no Brasil por "jogo da velha" ou "quadrado". As Hashtags são utilizadas para categorizar os conteúdos publicados nas redes sociais, ou seja, cria uma interação dinâmica do conteúdo com os outros integrantes da rede social, que estão ou são interessados no respectivo assunto publicado. Por se tornar um termo popular entre os usuários das mídias, a partir de junho de 2014 foi incorporado ao Oxford English Dictionary. As hashtags devem ser usadas como indexadores, facilitando buscas futuras por outros usuários (HASHTAG, 2014).

6 Ver: Resolução Conama nº 275, de 25 de abril de 2001 (BRASIL, 2001, p. 80).

$96 \frac{\text { Comunicação \& Inovação, PPGCOM/USCS }}{\text { v. 18, n. } 37 \text { (84-102) maio-ago } 2017}$ 
alguns bairros de Belém. Entre os temas a serem abordados nessas ações estão o gerenciamento sobre o destino dos resíduos sólidos e a reciclagem. Ela comentou que "as oficinas servirão tanto para mobilizar como para fazer com o que projeto seja discutido nas comunidades locais. Do mesmo modo, pretendo capacitar lideranças para que se articulem por meio do Facebook" (GIUSTI, 2016a).

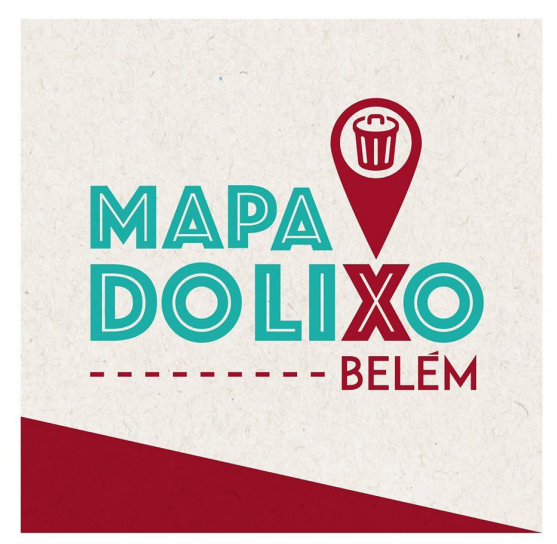

Figura 2. Lomarca "Mapa do Lixo - Belém"

Fonte: Página "Mapa do Lixo - Belém"

Ao se acessar a página do "Mapa do Lixo - Belém", observa-se que, além das oficinas propostas, há exposições e informações sobre arte, teatro-vídeo, teatro, cinema e espetáculos em prol da proteção ambiental da cidade de Belém. Nesse contexto, destaca-se o poder da arte, a sua relação com a humanidade e com as construções sociais (FERRAZ, 2015). As manifestações artísticas são socioculturamente construídas, refletindo o contexto de imersão dos agentes sociais e suas possibilidades de compreensão sobre si e o mundo.

$\mathrm{Na}$ contemporaneidade, as ações sociais e os movimentos de grupos demonstram esse caráter histórico-social das artes, especialmente quando esses agentes se valem de apresentações literárias, teatrais e musicais, de performances e instalações em espaços públicos, assim como no ciberespaço. Neste, as manifestações estéticas têm possibilitado reflexões dialógicas e éticas acerca de questões inerentes à vida social, tanto na dimensão individual quanto na coletiva. A partir da observação da plataforma digital "Mapa do Lixo - Belém”, podem-se depreender sentidos que apontam para uma conscientização sobre questões ambientais nas ruas do centro e da periferia da capital paraense por meio de ações artísticas e culturais.

No caso da referida página, o ciberativismo, entendido como um movimento que congrega ações coletivas coordenadas, mobilizadas e distribuídas coletivamente em rede interativa (LAZZARATO e NEGRI, 2001) vale-se do teatro, da literatura e 
da música para a mobilização de ações de combate à produção de lixos oriundos de resíduos domésticos e empresariais. Dessa forma, por meio da divulgação de registros fotográficos, os quais podem ser realizados e encaminhados por qualquer cidadão internauta, ocorre não apenas a publicização do problema social do acúmulo inapropriado de lixo e dos efeitos catastróficos dele decorrentes, como também a chamada para o comportamento inadequado e desrespeitoso para com a natureza e para com a sociedade em que vivemos.

Todavia, essas ações de divulgação e de chamada para o problema recebem um elemento perceptivo estético: o movimento social, que é apresentado pela comunidade virtual "Mapa do Lixo - Belém", produz eventos de declamações de poesias, de encenações de peças teatrais e de exibições de vídeos que reelaboram as imagens e as mensagens contidas nos registros fotográficos.

Nesse sentido, o site em tela desempenha uma comunicação virtual com o exercício do ciberativismo tomando as artes como mediação no processo de conscientização social sobre direitos e deveres de cidadania e de política pública em relação ao espaço urbano e ao espaço de convivências. Por meio da peça "Lixo à Vista! Uma aventura pirata", apresentada em abril de 2016, cujo "objetivo é abordar, através do teatro, a questão social relacionada à produção e à reciclagem do lixo, aliando o lúdico à conscientização ecológica" (GIUSTI, 2016b), a plataforma demonstra que a sensibilização coletiva dos internautas é possível através da arte.

Desse modo, essa comunidade virtual chama a atenção para a promoção da sustentabilidade no espaço urbano amazônico partindo de seu cotidiano, de seu conhecimento obtido pela experiência, que é ressignificado por meio de ações artísticas e culturais. Como mediações e instrumentos dialógicos, a arte e as plataformas digitais, então, possibilitam que o homem-cidadão-internauta-consumidor reflita sobre sua condição no mundo, sobre a repercussão de seus atos e condutas em relação ao lugar em que vive e em que se relaciona, tanto no plano on-line como no off-line.

A leitura da página permite concluir que se realizou a fusão da Comunicação de Interesse Público, por meio da mídia digital, com ações de ativismo, à medida que se tornou possível não apenas registrar fatos de desrespeito ambiental e social nas ruas de Belém, mas também participar ativamente desse quadro social e de sua transformação.

\section{Considerações finais}

O ponto de partida deste trabalho foi descrever alguns aspectos da Comunicação de Interesse Público e de ciberativismo nas ações de sustentabilidade da comunidade

$98 \frac{\text { Comunicação \& Inovação, PPGCOM/USCS }}{\text { v. 18, n. 37 (84-102) maio-ago } 2017}$ 
virtual "O Mapa do Lixo - Belém" no estado do Pará, Amazônia. Dessa forma, buscou-se discutir e mostrar dados e instrumentos teóricos que possibilitaram observar que, apesar de iniciativas de práticas sustentáveis na Amazônia, especialmente em Belém, as práticas de consumo urbano sem a conscientização de sustentabilidade ambiental podem afetar a qualidade de vida e a preservação do meio ambiente.

Essa ausência de Comunicação de Interesse Público para conscientização da sociedade que vive no perímetro urbano foi evidenciada nas entrevistas e leituras de documentos. Essa metodologia de investigação mostrou que os cidadãos ainda desconhecem seus direitos e obrigações, além de carecerem de políticas públicas mais abrangentes e de informações institucionais básicas como a educação ambiental. Além disso, não há parâmetros para as organizações privadas executarem ações sustentáveis de produtos com embalagens industrializadas sem critérios de reciclagem. As imagens postadas na página do Facebook "Mapa do Lixo - Belém" revelam que em vários bairros da cidade de Belém é possível encontrar lixo e entulho que poluem e obstruem ruas e canais.

Nesse sentido, o público que acessa a página tem contribuído com postagens e envio de imagens relacionados à temática ambiental, demonstrando suas críticas e opiniões, possibilitando, assim, a prática do ciberativismo. A escolha da mídia social Facebook não é por acaso. A pesquisa de consumo de mídia intitulada $6^{\circ}$ Mapa Mundial das Redes Sociais, que demonstra as principais redes sociais utilizadas em 2015, aponta que as três primeiras colocadas foram, por ordem de quantidade de usuários, Facebook (1,59 bi), YouTube ( 1 bi) e WhatsApp (1 bi). Atualmente, as redes sociais que ocupam as dez primeiras posições no ranking das mais populares no mundo todo somam juntas mais de 7 bilhões de usuários (BRASIL, 2016).

Este estudo identificou a falta generalizada de uma plataforma de informações institucionais do poder público com as diferentes organizações empresariais, públicas e privadas na elaboração de políticas públicas voltadas ao planejamento e à gestão dos resíduos sólidos.

Há ausência, também, de uma proposta de práticas comerciais sustentáveis para as organizações empresariais que vendem produtos naturais e industrializados. Nesse campo, há um verdadeiro vácuo e ausência de Comunicação de Interesse Público no setor ambiental, ou seja, o poder público não sinaliza interesse em discutir o assunto e, assim, as organizações que comercializam produtos, sejam naturais ou industrializados, não se veem responsáveis pelo uso de embalagens ecológicas e recicladas.

Do mesmo modo, não foram encontradas sistematizações comunicacionais para que os diferentes órgãos sejam mais eficientes na circulação da informação para manter 
a cidade limpa no espaço público, de forma que tais informações consigam ser realmente apropriadas pelos cidadãos.

Ser cidadão contemporâneo é entender o mundo numa perspectiva multidemensional, por meio de crenças, de manifestações culturais, de práticas sociopolíticas e de interação virtual. Nesse sentido, a plataforma digital "Mapa do Lixo - Belém” atende a algumas dessas perspectivas ao desenvolver a divulgação e a reflexão sobre a importância da participação dos internautas (agentes sociais) para a denúncia do problema do lixo e, ao mesmo tempo, para a necessidade de sua resolução, a qual não depende exclusivamente do poder público, e sim da mobilização e da ação dos cidadãos.

Desse modo, a Comunicação de Interesse Público, se bem promovida, contribui para desenvolver um importante processo educativo, visto que, por meio de tendências individuais e da informação, se estimula a sensibilidade emocional e mobiliza-se a formação de sentidos críticos para a conscientização individual e coletiva acerca das questões sociais e ambientais.

\section{Referências}

ASSOCIAÇÃO BRASILEIRA DE NORMAS TÉCNICAS. Amostragem de Resíduos e procedimento NBR 10007. São Paulo: ABNT, 1987.

ASSOCIAÇÃO BRASILEIRA DE LIMPEZA PÚBLICA E RESÍDUOS ESPECIAIS. Panorama dos resíduos sólidos no Brasil 2010. São Paulo: Abrelpe, 2010. Esse documento em documento no Programa PDF poderá ser solicitado a Abrelpe. Disponível em: $<$ http://www.abrelpe.org.br/panorama_edicoes.cfm>. Acesso em: 15 jun., 2017

ANTOUN, H. MALINI, F. A internet e a rua: Ciberativismo e mobilização nas redes sociais. Porto Alegre: Sulina. 2013.

BRASIL. Constituição (1988). Constituição da República Federativa do Brasil. Brasília, DF: Senado Federal, 1988. Disponível em: <http://www.planalto.gov.br/ccivil_03/Constituicao/Constituicao. htm>. Acesso em: 15 mar., 2017

Resolução Conama n ${ }^{\circ} 275$, de 25 de abril de 2001. Estabelece o código de cores para os diferentes tipos de resíduos, a ser adotado na identificação de coletores e transportadores, bem como nas campanhas informativas para a coleta seletiva. Diário Oficial da União. 19 jun. 2001. Seção 1. p., 80 .

. Caminhos para a sustentabilidade. Programa Piloto para Proteção das Florestas Tropicais do Brasil (PPG7). Brasília, DF: Ministério do Meio Ambiente. 2009a. Disponível em: <http://bit. ly/2p631jw>. Acesso em: 20 jun., 2016.

$100 \frac{\text { Comunicação \& Inovação, PPGCOM/USCS }}{\text { v. 18, n. } 37 \text { (84-102) maio-ago } 2017}$ 
Catálogo de publicações do Programa Piloto para Proteção das Florestas Tropicais do Brasil: 17 anos de atuação na Amazônia e Mata Atlântica. Brasília, DF: Ministério do Meio Ambiente. 2009b. Disponível em: <http://bit.ly/2ueqWUh>. Acesso em: 20 jun., 2016.

Pesquisa brasileira de mídia 2016: hábitos de consumo de mídia pela população brasileira. Brasília, DF: Secretaria Especial de Comunicação Social da Presidência da República (Secom). 2016. Disponível: <https://goo.gl/XrtwBw> Acesso em: 14 jul., 2017.

BRANDÃO, Elizabeth. P. Conceito de comunicação pública. In: DUARTE, J. (Org.). Comunicação pública: Estado, mercado, sociedade e interesse público. 2. ed. São Paulo: Atlas, 2009.

DUARTE, J. Instrumentos de comunicação pública. In: DUARTE, J. (Org.). Comunicação pública: Estado, mercado, sociedade e interesse público. 2. ed. São Paulo: Atlas, 2009.

FERRAZ, A. M. O homem, o real e as questões. In: Seminário Internacional de Filosofia, Poética e Educação, 2. 2015, Juiz de Fora. Anais. Faculdade de Educação da Universidade Federal de Juiz de Fora, out. 2015. Disponível em: <http://bit.ly/2ptDpQs>. Acesso em: 22 maio, 2016.

GIUSTI, D. Dominik Giusti: depoimento [20 set. 2016]. Entrevistador: Moacir Cristhie Pereira do Nascimento. Belém, 2016a.

D. Mapa do Lixo - Belém. Facebook. 2016b. Disponível em: <http://bit.ly/2q3aynF>. Acesso em: set., 2016.

HASHTAG. Oxford English Dictionary, 2014.

INSTITUTO BRASILEIRO DE GEOGRAFIA E ESTATÍSTICA (IBGE). Censo 2010. Disponível em: $<$ http://bit.ly/1Kxx7Bq>. Acesso em: 20 maio. 2015.

Divisão política: Amazônia Legal representa 59\% do território brasileiro. 2013. Disponível em: $<$ http://www.ibge.gov.br/home/geociencias/geografia/mapas_doc5.shtm>. Acesso em: 15 jun., 2016.

JACOBI. P. Meio ambiente urbano e sustentabilidade: alguns elementos para a reflexão. In: CAVALCANTI, C. V. (Org.). Meio ambiente, desenvolvimento sustentável e políticas públicas. São Paulo: Cortez, 1997. p. 384-390.

LAZZARATO, M.; NEGRI, A. Trabalho Imaterial: formas de vida e produção de subjetividade. Rio de Janeiro: DP\&A, 2001.

LÉVY, Pierre. Cibercultura. São Paulo: Ed. 34, 1999.

MAIA, M. E., GAIA, A. Impactos ambientais causados pelos resíduos de construção civil no município de Belém. 2012. 58 f. Trabalho de conclusão de curso (Graduação em Engenharia Civil) Universidade da Amazônia, Belém, 2012.

MATOS, H. Comunicação Pública, Democracia e Cidadania: o caso do Legislativo. Líbero: revista acadêmica de pós-graduação. São Paulo: Fundação Cásper Líbero, v. 2, n. 3-4, 1999.

OLIVEIRA, R. M. M. Gestão e gerenciamento de resíduos sólidos urbanos: o programa de coleta seletiva da região metropolitana de Belém - PA. 2012. 113 f. Dissertação (Mestrado em Desenvolvimento e Meio Ambiente Urbano) - Universidade da Amazônia, Belém, 2012. 
PARÁ (Estado). Lei Ordinária nº 8899, de 26 de dezembro de 2011. Institui o Plano de Gerenciamento Integrado de Resíduos Sólidos do Município de Belém - PGRS e dá outras providências. Diário Oficial do Município. Belém, 26 dez. 2011. Segundo caderno.

POLÍTICA NACIONAL DE RESÍDUOS SÓLIDOS (PNRS). 2a Ed. Revisada e atualizada. Disponível: $<$ http://fld.com.br/catadores/pdf/politica_residuos_solidos.pdf> Acesso em: 14 jul., 2017.

PRESSLER, N. Comunicação e Meio Ambiente: agências de cooperação internacional e projetos socioambientais na Amazônia. Belém: Unama; Manaus: UEA, 2012.

PROJETO NOVA CARTOGRAFIA SOCIAL DA AMAZÔNIA (PNCSA). Pescadores e extrativistas das Ilhas ao Sul de Belém. Fascículo, 29., Belém: Unamaz; UFPA, 2010.

RECUERO, R. Redes sociais na Internet. Porto Alegre: Sulina, 2009.

SECRETARIA MUNICIPAL DE SANEAMENTO DE BELÉM (SESAN). Prefeitura fiscaliza bairros em operação que coíbe despejo irregular de lixo. 2016. Disponível em: <http://bit.ly/2qEeNTv>. Acesso em: 9 jun., 2016. 